Delft University of Technology

\title{
MEMS enabled fast time-resolved X-ray diffraction characterization platform for copper nanoparticle sintering in heterogeneous integration applications
}

Zhang, Boyao; Wei, Jia; Bottger, Amarante J.; van Zeijl, Henk W.; Sarro, Pasqualina M.; Zhang, GuoQi

DOI

10.1109/TRANSDUCERS.2019.8808192

Publication date

2019

Document Version

Final published version

Published in

2019 20th International Conference on Solid-State Sensors, Actuators and Microsystems and Eurosensors XXXIII, TRANSDUCERS 2019 and EUROSENSORS XXXIII

\section{Citation (APA)}

Zhang, B., Wei, J., Bottger, A. J., van Zeijl, H. W., Sarro, P. M., \& Zhang, G. (2019). MEMS enabled fast time-resolved X-ray diffraction characterization platform for copper nanoparticle sintering in heterogeneous integration applications. In 2019 20th International Conference on Solid-State Sensors, Actuators and Microsystems and Eurosensors XXXIII, TRANSDUCERS 2019 and EUROSENSORS XXXIII: Proceedings (pp. 1772-1775). [8808192] (2019 20th International Conference on Solid-State Sensors, Actuators and Microsystems and Eurosensors XXXIII, TRANSDUCERS 2019 and EUROSENSORS XXXIII). IEEE . https://doi.org/10.1109/TRANSDUCERS.2019.8808192

\section{Important note}

To cite this publication, please use the final published version (if applicable).

Please check the document version above.

\section{Copyright}

Other than for strictly personal use, it is not permitted to download, forward or distribute the text or part of it, without the consent of the author(s) and/or copyright holder(s), unless the work is under an open content license such as Creative Commons. 
Green Open Access added to TU Delft Institutional Repository

'You share, we take care!' - Taverne project

https://www.openaccess.nl/en/you-share-we-take-care

Otherwise as indicated in the copyright section: the publisher is the copyright holder of this work and the author uses the Dutch legislation to make this work public. 


\title{
MEMS ENABLED FAST TIME-RESOLVED X-RAY DIFFRACTION CHARACTERIZATION PLATFORM FOR COPPER NANOPARTICLE SINTERING IN HETEROGENEOUS INTEGRATION APPLICATIONS
}

\author{
Boyao Zhang ${ }^{1}$, Jia Wei ${ }^{2}$, Amarante J. Böttger ${ }^{3}$, Henk W. van Zeijl ${ }^{1}$, Pasqualina M. Sarro ${ }^{1}$, and \\ Guoqi Zhang ${ }^{l}$ \\ ${ }^{1}$ Department of Microelectronics, Delft University of Technology, Delft, the Netherland \\ ${ }^{2}$ Else Kooi Lab, Delft University of Technology Delft, the Netherland \\ ${ }^{3}$ Department of Material Science and Engineering, Delft University of Technology, Delft, the \\ Netherland
}

\begin{abstract}
We report the design, fabrication and experimental investigation of a MEMS micro-hotplate (MHP) for fast time-resolved X-ray diffraction (TRXRD) study of $\mathrm{Cu}$ nanoparticle paste (nanoCu paste) sintering process. The device and its system are designed to have a $60 \mathrm{~ms}$ minimum time interval, uniform temperature distribution and variant gas environments. A TRXRD study of nanoCu paste sintering at $200{ }^{\circ} \mathrm{C}$ in $\mathrm{H}_{2}-\mathrm{N}_{2}$ gas mixture was done using this device. With $1 \mathrm{sec}$ interval, $\mathrm{Cu}_{8} \mathrm{O}$ reduction and $\mathrm{Cu}$ crystallization in sintering is observed. Results can be combined with other studies to optimize material design and process development.
\end{abstract}

\section{KEYWORDS}

MEMS, Microhotplate, TRXRD, Copper nanoparticle paste

\section{INTRODUCTION}

Low temperature sintering of metallic nanoparticle paste, such as nanoCu paste, has a great potential as interconnect solution in heterogeneous integration [1]. Experimental time-dependent insight of the sintering process is essential for both process optimization and material development [2,3]. This time-dependent study is however very limitedly reported, even for Ag nanoparticle paste, which is already developed and applied in interconnect solutions for high reliability and performance driven applications. Xu used real-time electrical resistance measurement to study sintering process of Ag nanoparticle paste [2]. The corresponding time-dependent $\mathrm{Ag}$ nanoparticle structure information was not reported and correlated. Milhet applied an in-situ X-ray nanotomography method to evaluate microstructure change of Ag nanoparticle paste during thermal exposure after sintering [3]. However, the experimental conditions and specimen geometry are far from real conditions in the envisioned applications. As an emerging material and technology, more detailed and systematic study of nanoCu paste sintering process under real application conditions needs to be performed.

To mimic and study the sintering process as in real applications, nanoCu paste (particle size $<100 \mathrm{~nm}$ ) needs to be processed with micrometer thickness, in gas environment. Transmission electron microscope (TEM) reveals the particle behavior at atomic level [4,5]. However, it is limited to thin sample thickness and ultra-high vacuum environment. On the other hand, traditional XRD is affordable and penetrative to micrometer sample thickness. However, it is time consuming (a few minutes to hours) to collect precise material information. Due to size effect and complexity of structure, nanoparticles study requires even more time and sophisticated methods. Therefore, it is not suitable to observe fast reaction processes. Modern synchrotron techniques enables ultra-fast XRD detection $[6,7]$. It brings time resolution down to femtoseconds. However, the equipment and accessories are costly and not frequently available in most laboratories.

In this paper, a MEMS-enabled fast time-resolved XRD (TRXRD) method is proposed to obtain insight knowledge about nanoCu paste sintering.

\section{DESCRIPTION OF THE NEW METHOD AND SYSTEM}

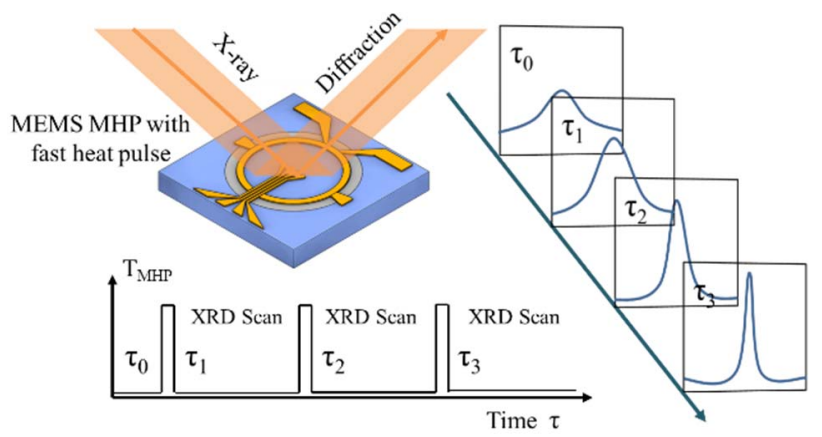

Figure 1: The concept of MEMS enabled time-resolved Xray diffraction for material characterization.

TRXRD is defined as a method for detecting dynamic position and intensity of diffracted XRD pattern as a function of time, by using a short pulse X-ray beam at the sample [7]. High intensity synchrotron radiation beams enables the necessary time interval to reveal intermediate states of materials. Instead of using short pulses of synchrotron X-ray beam, a MEMS micro-hotplate (MHP) device is introduced to enable TRXRD in milli-seconds 
(ms), using conventional XRD facilities. Fine, accurate XRD scans are performed during frozen states (Fig. 1). By switching alternatively between activated and frozen states, a series of XRD patterns, thus material details, for a specific dynamic process can be obtained as a function of time. To enable a milli-seconds TRXRD, the device contains an onchip MHP to enable fast temperature control (typically tens of milli-seconds) on micro-sized samples placed on top of the MHP surface. This allows a fast switching of temperature sensitive reactions between activated and frozen states.

Typically, the size of a MHP with suspended is below $0.5 \mathrm{~mm}$ in diameter. A temperature difference of $30-50{ }^{\circ} \mathrm{C}$ from edge to the center, when the MHP temperature is between $300-400{ }^{\circ} \mathrm{C}$, is generated [8-10]. For a sintering process study under TRXRD, a $0.5 \mathrm{~mm}$ diameter heating area hardly provides enough signal for detection. In addition, nanoCu paste sintering takes place below $300^{\circ} \mathrm{C}$, more than $10 \%$ of temperature variation can have a strong effect on the final characterization results. To ensure a homogeneous reaction across a large XRD detection area, a $50 \mu \mathrm{m}$ thick single crystal silicon membrane $(1 \mathrm{~mm}$ in diameter for typical X-ray beam size) is introduced to have uniform horizontal thermal distribution (Fig. 2b). Furthermore, thick oxide blocks as horizontal thermal isolation is included in the design to reduce power consumption, and constrain temperature uniformity within MHP area [11]. Thus, a millisecond-level fast temperature response needs to be achieved to ensure a fast temperature switching. By accurate control of current value, device can switch between activated and frozen states.

\section{Finite element simulation}

Table 1: Micro-hotplate average temperature and deviation from FEM simulation results

\begin{tabular}{c|c|c|c}
\hline $\mathrm{T}_{\mathrm{avg}}\left({ }^{\circ} \mathrm{C}\right)$ & $\mathrm{T}_{\max }\left({ }^{\circ} \mathrm{C}\right)$ & $\mathrm{T}_{\min }\left({ }^{\circ} \mathrm{C}\right)$ & Deviation \\
\hline 41.67 & 41.97 & 41.17 & $1.39 \%$ \\
\hline 106.64 & 107.83 & 104.64 & $2.18 \%$ \\
\hline 214.82 & 217.51 & 210.34 & $2.43 \%$ \\
\hline 366.25 & 371.03 & 358.28 & $2.54 \%$
\end{tabular}

(a)

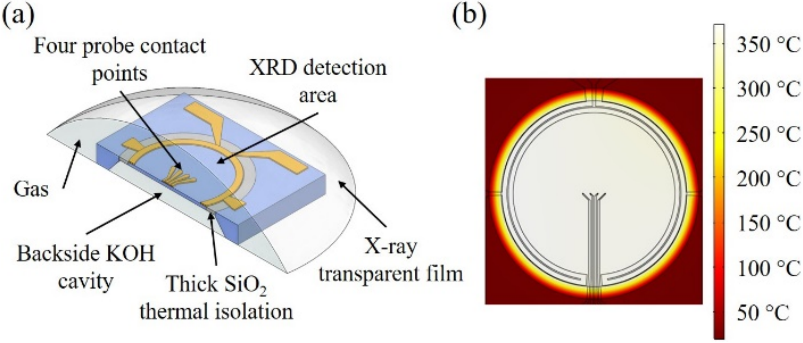

Figure 2: (a) Schematic structure of MHP. (b) FEM simulation result of MHP temperature distribution when input current is $0.2 \mathrm{~A}$.
To evaluate the temperature distribution along the MHP area, a finite element modeling (FEM) simulation was performed using COMSOL Multiphysics, v5.2.

The simulated temperature distribution with different average temperature and deviations are shown in Table 1 and Figure 2(b). The temperature deviation from the average value is $2.54 \%$ within the hotplate area, up to a maximum average working temperature of $366.25{ }^{\circ} \mathrm{C}$. Typically, the sintering of nanoCu paste is between $200-$ $300{ }^{\circ} \mathrm{C}$. In this temperature range, MHP has $2-2.5 \%( \pm 5$ $-7{ }^{\circ} \mathrm{C}$ ) deviation from the average temperature. This is a relatively small deviation for sintering process. Temperature uniformity in this device achieves requirement for sintering process study.

\section{FABRICATION}

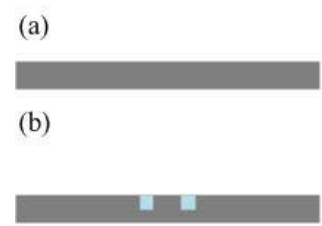

(c)
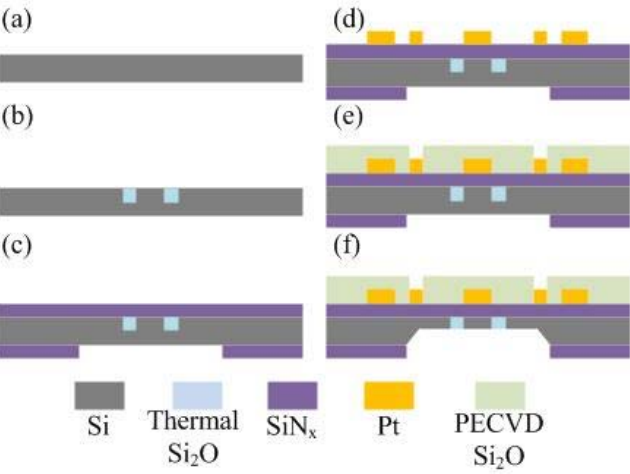

Figure 3: The main steps of the fabrication process. (a-b) Formation of thick silicon oxide blocks for thermal isolation by using DRIE and thermal oxidation. (c-d) Surface smoothening and metallization. (e) Passivation layer deposition and contact pads opening. (f) Backside cavity etching in a $\mathrm{KOH}$ solution

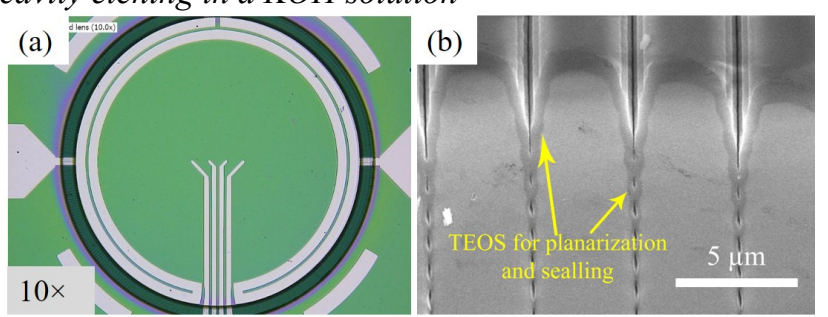

Figure 4: (a) Optical image (close-up) of a fabricated MHP. (b) SEM cross-section image of the thick oxide blocks used for lateral thermal isolation.

A bulk-micromachining process is developed (Fig. 3) for the device fabrication. A fabricated device is shown in Figure 4. A $525 \mu \mathrm{m}$ thick Si wafer was used as starting material (Fig. 3a). A thick silicon oxide lateral thermal isolation structure ( $50 \mu \mathrm{m}$ deep, $100 \mu \mathrm{m}$ wide) is fabricated using deep reactive ion etching (DRIE) and wet thermal oxidation (Fig. 3b). Figure $4 \mathrm{~b}$ shows the cross section of lateral thermal isolation structure. $300 \mathrm{~nm}$ of $\mathrm{SiN}_{\mathrm{x}}$ was deposited by low pressure chemical vapor deposition (LPCVD). It is used as isolation layer between $\mathrm{Si}$ and $\mathrm{Pt}$, diffusion layer between $\mathrm{Si}$ and nanoCu and as a hard mask 
for Si cavity etching on the backside (Fig. 3c). A $200 \mathrm{~nm}$ $\mathrm{Pt}$ metal layer, which is the MHP metal layer, was evaporated and patterned by lift-off method (Fig. 3d). A $\mathrm{SiO}_{2}$ passivation layer of was deposited by plasma enhanced chemical vapor deposition (PECVD). Contact pads were opened by using reactive ion etching, with photoresist as mask layer (Fig 3e). Si cavity on the backside was etched by isotropic wet etching with $\mathrm{KOH}$ solution (Fig. 3f). It landed on predefined $50 \mu \mathrm{m}$ thick $\mathrm{SiO}_{2}$ thermal isolation block. A $50 \mu \mathrm{m}$ thick Si membrane was created.

\section{EXPERIMENTAL RESULTS}

\section{Transient measurement of stabilization time}

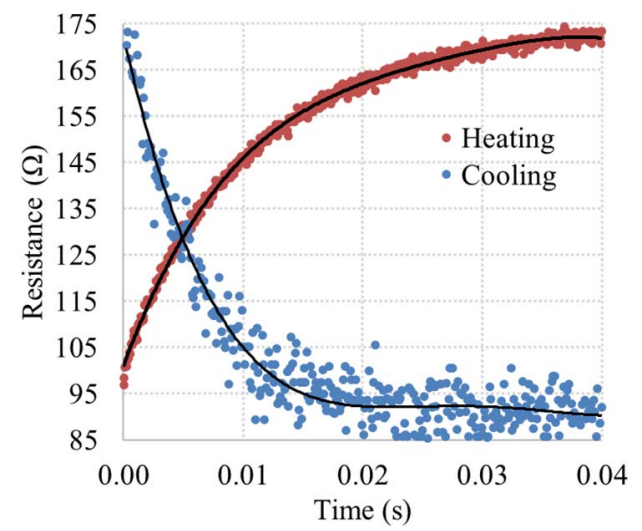

Figure 5: Transient measurement of MHP device resistance variation during heating and cooling

To characterize the time constant of device temperature response, the transient change of MHP resistance is measured as an indication of the average temperature in the heating area. By giving a short current pulse, transient change of MHP voltage, namely the MHP resistance, as a function of time, can be measured. Fabricated MHP is probed with a probe station (Cascade Microtech). SMU (Agilent 4156C parameter analyzer) and an oscilloscope are connected to the probe station. The SMU is used to supply accurate current pulse. An oscilloscope is used to measure transient change of MHP resistance in both heating and cooling process. The results are shown in Figure 5. The time to reach $90 \%$ of stabilized value is determined as heating or cooling time. In the resistance measurement, it takes approximately $35 \mathrm{~ms}$ and $25 \mathrm{~ms}$ to stabilize for heating and cooling respectively to reach $90 \%$ of total resistance change. Consequently, the time resolution of the device for time-resolved characterization is $60 \mathrm{~ms}$.

\section{Sintering study}

To validate the concept, a layer of nanoCu paste (particle size $<100 \mathrm{~nm}$ ) with an average thickness of $1.3 \mathrm{um}$ was applied on the MHP surface using drop-casting method (Fig. 6). Controlled gas environment is created by using a gas cell mounted on XRD equipment (Bruker D8, Co K $\alpha$ radiation, $\lambda=1.79 \quad$ ). On top of the gas cell, $\mathrm{A}$ polypropeiene film (thickness $<13 \mu \mathrm{m}$ ) is used as X-ray transparent film to allow conventional XRD measurement, while keeping gas cell properly sealed. A SMU (Keithley 2602B) is connected to the device. Controlled current pulses were given to obtain multiple activated states with desired temperature and duration. A dedicated sintering process, consisting of several activated and frozen states in alternative sequences, is performed under a controlled forming gas environment $\left(5 \% \mathrm{H}_{2}+95 \% \mathrm{~N}_{2}\right)$. Heat pulses applied in this experiment is $1 \mathrm{sec}$ at $200{ }^{\circ} \mathrm{C}$. XRD scans with $0.02^{\circ}$ increment, 1 sec step time, were performed during the frozen states $\left(25^{\circ} \mathrm{C}\right)$. Each XRD scan takes around $10 \mathrm{~min}$. Three heat pulses were applied in this experiment, which correspond to series of scan patterns in Figure 7.

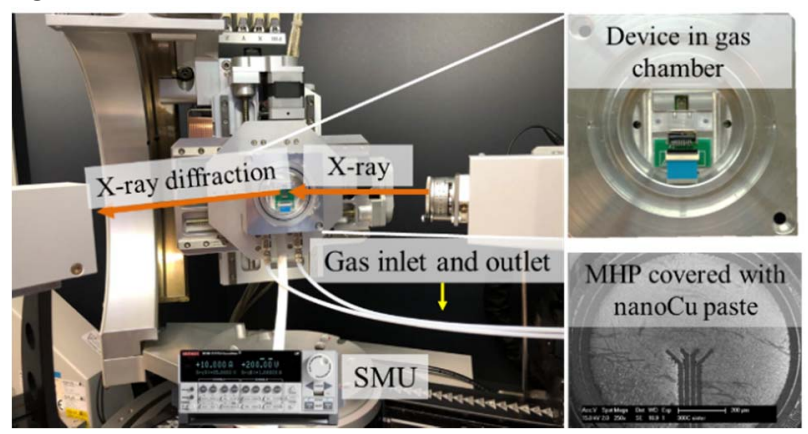

Figure 6: Time resolved XRD experiment set-up. Chip is connected to source-measurement unit (SMU) for temperature control and real-time measurement. The SEM image on the right corner shows a MHP device covered with nanoCu paste.

In Figure 7, " $0 \mathrm{~s}$ " XRD pattern, which represents the status of the nanoCu paste before sintering, indicating the existence of a small amount of surface oxide $\left(\mathrm{Cu}_{8} \mathrm{O}\right)$. In general, small amounts of surface oxides might be introduced from solution based nanoparticle synthesis. There are two inserts in Figure 7, presenting detail peak information about $\mathrm{Cu}_{8} \mathrm{O}$ and $\mathrm{Cu}$ (111) respectively. Based on the series of diffraction patterns, a full-width-halfmaximum (FWHM) analysis of $\mathrm{Cu}$ (111) peak and corresponding crystal size is performed and results are presented in Figure 8. According to the insert of $\mathrm{Cu}_{8} \mathrm{O}$ peak, it decreased after first heat pulse at $200{ }^{\circ} \mathrm{C}$. It indicates that $\mathrm{Cu}_{8} \mathrm{O}$ is reduced in the first second heat pulse. In addition, $\mathrm{Cu}$ (111) peak width (FWHM) decreased due to crystal growth (Fig. 8) in the first heat pulse. With reduction of $\mathrm{Cu}_{8} \mathrm{O}, \mathrm{Cu}$ atoms can diffuse between neighboring nanoparticles. This probably leads to the initial state of neck formation in sintering process. $\mathrm{Cu}$ (111) crystalline size also experienced an increase, consequently. In the following heat pulses (1-3 s), FWHM does not decrease much. In contrast, it increases slightly. This is probably contributed by overlapping of background at $2 \theta=50^{\circ}$ and $2 \theta=52^{\circ}$. These background signals are possibly obtained from the $\mathrm{SiO}_{2}$ on the substrate of MHP. 


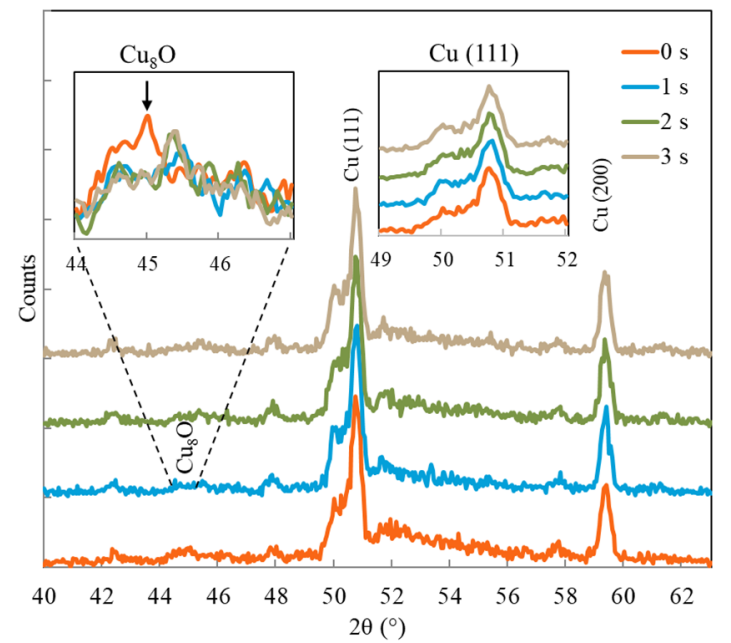

Figure 7: Time-resolved XRD patterns during $\mathrm{Cu} / \mathrm{Cu}_{8} \mathrm{O}$ nanoparticle paste sintering process.

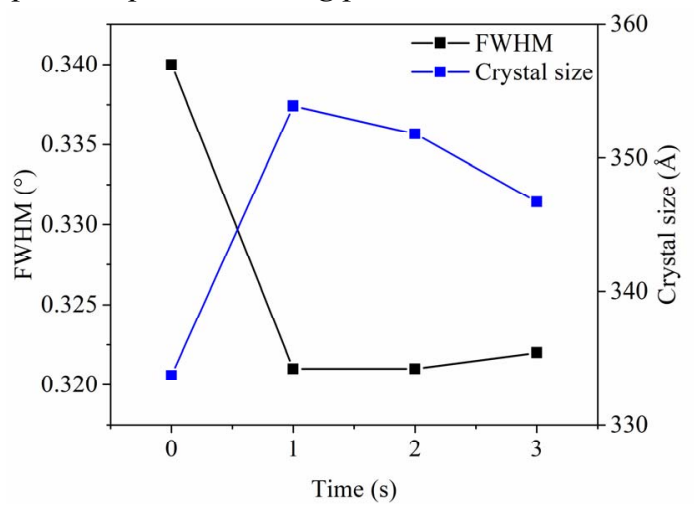

Figure 8: Full-width-half-maximum (FWHM) reduction and corresponding crystal size growth of $\mathrm{Cu}$ (111) peak can be observed.

Since $\mathrm{Cu}$ has a relatively low diffusion coefficient, it might take a longer time to complete the sintering process. A longer time range study of nanoCu paste sintering needs therefore to be followed. In addition, various sintering temperatures and the heating rate effect on the sintering process can be also explored further. Besides XRD patterns, real-time electrical resistance measurement of the sample will also be included in future work to provide a more complete and accurate understanding of the sintering process.

\section{CONCLUSION}

In this study, a MEMS based MHP with a silicon oxide lateral thermal isolation block is designed and fabricated. With this MEMS MHP, a 60 ms minimum time interval and uniform temperature distribution are achieved. A fast TRXRD study of a nanoCu paste sintering process in various gas environments can be achieved with this characterization platform. To validate the capability of the proposed nanomaterial characterization system, $200{ }^{\circ} \mathrm{C}, 1$ sec heat pulses for $3 \mathrm{sec}$ in $5 \% \mathrm{H}_{2}+95 \% \mathrm{~N}_{2}$ is applied on a nanoCu thin film. In the first $1 \mathrm{sec}$ interval, oxide $\left(\mathrm{Cu}_{8} \mathrm{O}\right)$ reduction is observed, followed by $\mathrm{Cu}$ (111) crystal growth due to $\mathrm{Cu}$ atom diffusion between $\mathrm{Cu}$ NP. This platform provides insights of nanoCu paste low temperature sintering. These promising results allow further studies on optimization of the sintering process and nanoparticle development.

\section{ACKNOWLEDGMENT}

This research was carried out under project number T16.017 in the framework of the Research Program of the Materials innovation institute (M2i) (www.m2i.nl). XRD experiment is advised and supported by department of materials science and engineering, Delft University of Technology.

\section{REFERENCE}

[1] B. Y. Zhang, Y. C. P. Carisey, A. Damian, R. H. Poelma, H. W. van Zeijl, and G. Q. Zhang, "3D Interconnect technology based on low temperature copper nanoparticle sintering," presented at the 2016 17th International Conference on Electronic Packaging and Tehcnology, Wuhan, China, 2016.

[2] D. E. Xu, J. B. Kim, M. D. Hook, J. P. Jung, and M. Mayer, "Real time resistance monitoring during sintering of silver paste," Journal of Alloys and Compounds, vol. 731, pp. 504514, 2018/01/15/2018.

[3] X. Milhet, A. Nait-Ali, D. Tandiang, Y. J. Liu, D. Van Campen, V. Caccuri, et al., "Evolution of the nanoporous microstructure of sintered $\mathrm{Ag}$ at high temperature using insitu X-ray nanotomography," Acta Materialia, vol. 156, pp. 310-317, 2018/09/01/2018.

[4] M. Yeadon, J. Yang, R. S Averback, J. Bullard, and M. J Gibson, In-Situ TEM Study of the Sintering of Copper Nanoparticles on (001) Copper vol. 153, 1997.

[5] M. Hummelgård, R. Zhang, H.-E. Nilsson, and H. Olin, "Electrical Sintering of Silver Nanoparticle Ink Studied by In-Situ TEM Probing," PLOS ONE, vol. 6, p. e17209, 2011.

[6] C. Rischel, A. Rousse, I. Uschmann, P.-A. Albouy, J.-P. Geindre, P. Audebert, et al., "Femtosecond time-resolved Xray diffraction from laser-heated organic films," Nature, vol. 390, p. 490, 1997.

[7] A. Ziegler, H. Graafsma, X. F. Zhang, and J. W. Frenken, Insitu Materials Characterization: Across Spatial and Temporal Scales: Springer-Verlag Berlin Heidelberg, 2014.

[8] M. E. Castagna, R. Modica, S. Cascino, M. Moschetti, V. Cerantonio, A. Messina, et al., "A high stability and uniformity W micro hot plate," Sensors and Actuators A: Physical, vol. 279, pp. 617-623, 2018/08/15/ 2018.

[9] Q. Liu, G. Ding, Y. Wang, and J. Yao, "Thermal Performance of Micro Hotplates with Novel Shapes Based on SingleLayer SiO Suspended Film," Micromachines, vol. 9, p. 514, 2018

[10] L. Mele, F. Santagata, E. Iervolino, M. Mihailovic, T. Rossi, A. T. Tran, et al., "A molybdenum MEMS microhotplate for high-temperature operation," Sensors and Actuators A: Physical, vol. 188, pp. 173-180, 2012/12/01/ 2012.

[11] C. Zhang and K. Najafi, "Fabrication of thick silicon dioxide layers for thermal isolation," Journal of Micromechanics and Microengineering, vol. 14, pp. 769-774, 2004. 